\title{
Dual action of the cannabinoid receptor 1 ligand arachidonyl-2'-chloroethylamide on calcitonin gene-related peptide release
}

\author{
Isabella Mai Christiansen 1,2, Jacob C. A. Edvinsson 1,3, Philip V. Reducha ${ }^{1,2}$, Lars Edvinsson ${ }^{1,4}$ and \\ Kristian Agmund Haanes ${ }^{1,2^{*}}$ (D)
}

\begin{abstract}
Background: Based on the current understanding of the role of neuropeptide signalling in migraine, we explored the therapeutic potential of a specific cannabinoid agonist. The aim of the present study was to examine the effect of the synthetic endocannabinoid (eCB) analogue, arachidonyl-2'-chloroethylamide (ACEA), on calcitonin gene-related peptide (CGRP) release in the dura and trigeminal ganglion (TG), as cannabinoids are known to activate $\mathrm{G}_{\mathrm{i} / \mathrm{o}}$-coupled cannabinoid receptors type 1 (CB1), resulting in neuronal inhibition.
\end{abstract}

Methods: The experiments were performed using the hemi-skull model and dissected TGs from male Sprague-Dawley rats. CGRP release was induced by either $60 \mathrm{mMK}^{+}$(for depolarization-induced stimulation) or $100 \mathrm{nM}$ capsaicin (for transient receptor potential vanilloid 1 (TRPV1) -induced stimulation) and measured using an enzyme-linked immunosorbent assay. The analysis of CGRP release data was combined with immunohistochemistry in order to study the cellular localization of CB1, cannabinoid receptor type 2 (CB2), CGRP and receptor activity modifying protein 1 (RAMP1), a subunit of the functional CGRP receptor, in the TG.

Results: CB1 was predominantly expressed in neuronal somas in which colocalization with CGRP was observed. Furthermore, CB1 exhibited colocalization with RAMP1 in neuronal A $\delta$-fibres but was not clearly expressed in the CGRP-immunoreactive C-fibres. CB2 was mainly expressed in satellite glial cells and did not show substantial colocalization with either CGRP or RAMP1. Without stimulation, $140 \mathrm{nM}$ ACEA per se caused a significant increase in CGRP release in the dura but not TG, compared to vehicle. Furthermore, $140 \mathrm{nM}$ ACEA did not significantly modify neither $\mathrm{K}^{+}$- nor capsaicin-induced CGRP release. However, when the TRPV1 blocker AMG9810 (1 mM) was coapplied with ACEA, $\mathrm{K}^{+}$-induced CGRP release was significantly attenuated in the TG and dura.

Conclusions: Results from the present study indicate that ACEA per se does not exhibit antimigraine potential due to its dual agonistic properties, resulting in activation of both CB1 and TRPV1, and thereby inhibition and stimulation of CGRP release, respectively.

Keywords: Cannabinoid receptors, CGRP, Immunohistochemistry, Trigeminal ganglion, ACEA

*Correspondence: khaa0039@regionh.dk

1 Department of Clinical Experimental Research, Glostrup Research Institute, Rigshospitalet, Glostrup, Denmark

Full list of author information is available at the end of the article

\section{Introduction}

Migraine is a highly debilitating neurological condition linked to the sensory innervation of cranial blood vessels by the trigeminal nerves, together known as the trigeminovascular system (TVS). A pioneering study revealed that plasma levels of calcitonin gene-related original author(s) and the source, provide a link to the Creative Commons licence, and indicate if changes were made. The images or other third party material in this article are included in the article's Creative Commons licence, unless indicated otherwise in a credit line to the material. If material is not included in the article's Creative Commons licence and your intended use is not permitted by statutory regulation or exceeds the permitted use, you will need to obtain permission directly from the copyright holder. To view a copy of this licence, visit http://creativecommons.org/licenses/by/4.0/. The Creative Commons Public Domain Dedication waiver (http://creativeco mmons.org/publicdomain/zero/1.0/) applies to the data made available in this article, unless otherwise stated in a credit line to the data. 
peptide (CGRP), a vasodilator found in trigeminal neurons, increase significantly in craniovascular regions during the headache phase of migraine attacks, suggesting a crucial role for CGRP in migraine pathology [1].

Previous research has demonstrated CGRP release from the dura, the trigeminal ganglion (TG) and the trigeminal nucleus caudalis (TNC) in rats [2-6]. The TNC constitutes the major relay station for nociceptive afferent input from peripheral cranial structures, and is located in the brainstem in the trigeminocervical complex (TCC) [7-9]. According to the current view on migraine pathophysiology, hypothalamic activation during the premonitory phase of a migraine attack results in activation of the TNC, which in turn leads to activation of the TG. Hereafter, CGRP is released from the TG, resulting in vasodilation $[10,11]$.

CGRP is localized to small and medium sized (30$60 \mu \mathrm{m})$ neuronal somas and varicose, unmyelinated C-fibres [12], from which it is directly released [13]. $\mathrm{C}$-fibres run parallel to $\mathrm{A} \delta$-fibres in the TG and dura, and since $A \delta$-fibres are the only peripheral nerve fibres known to express the CGRP receptor (CLR/RAMP1), it has been suggested that the pain experienced by migraineurs originates from $A \delta$-fibres [11].

Activation of the CGRP receptor in the TG has been shown to implicate several signalling pathways known to mediate downstream physiological and pathophysiological effects. Among these is the cyclic adenosine monophosphate (cAMP) pathway, which is currently considered an antimigraine target $[10,11]$. Triptans were originally developed for their vasoconstrictive properties, and later found to act by reducing intracellular cAMP levels through activation of $5-\mathrm{HT}_{1 \mathrm{~B} / \mathrm{D}}$ [10]. In spite of their success, $25 \%$ of migraine patients display unresponsiveness to triptans and $40 \%$ of migraine attacks are not alleviated by triptan intervention [14], thus highlighting the need for alternative drugs for the acute treatment of migraine. Further, the contraindication of triptans for migraineurs with cardiovascular disorders prompted the development of Lasmiditan, a specific $5-\mathrm{HT}_{1 \mathrm{~F}}$ receptor agonist, which does not have vasoconstrictive effects [10, 15]. Although Lasmiditan does not activate $5 \mathrm{HT}_{1 \mathrm{~B}}$, recent data suggest that part of the Lasmiditan effect might partially be through $5 \mathrm{HT}_{1 \mathrm{D}}$ activation [16]. The $5-\mathrm{HT}_{1 \mathrm{~B} / 1 \mathrm{D} / 1 \mathrm{~F}}$ receptor subtypes are all $\mathrm{G}_{\mathrm{i} / \mathrm{o}}$-coupled G-protein coupled receptors (GPCRs) and elicit inhibitory effects on the adenylate cyclase (AC), causing a decrease in intracellular cAMP and thereby CGRP release [17]. Interestingly, the purinergic $\mathrm{P}_{2} \mathrm{Y}_{13}$ receptor, with adenosine diphosphate (ADP) as its ligand, also exhibits $\mathrm{G}_{\mathrm{i} / \mathrm{o}}$-coupling and has been shown to suppress CGRP release with results similar to that of Sumatriptan in preclinical models of migraine [5].
The endocannabinoid system (ECS) has been found in even the most primitive animals with a neuronal network, such as Hydra of the phylum Cnidaria, considered to be the first animal species possessing a neuronal network, thus illustrating the phylogenetic ancientness of the ECS $[18,19]$. The two major GPCRs in the ECS are cannabinoid receptor type 1 (CB1) and cannabinoid receptor type 2 (CB2). CB1 is expressed in most brain structures as well as in the peripheral nervous system (PNS), while CB2 expression is mainly restricted to immune cells of central and peripheral tissues $[20,21]$. The endocannabinoids (eCBs) 2-arachidonoylglycerol (2-AG) and $\mathrm{N}$-arachidonoylethanolamine (Anandamide, AEA) are well characterized agonists of CB1 and CB2 [22].

Immunohistochemistry (IHC) on different regions of the rat brain has previously demonstrated presynaptic localization of CB1, indicating a role in regulation of neurotransmission $[22,23]$. Indeed, eCBs are viewed as key regulators of synaptic function in the central nervous system (CNS). Their role in retrograde suppression of presynaptic neurotransmitter release has been well established, and studies provide evidence that presynaptic CB1 activation can lead to inhibition of neurotransmitter release (e.g., glutamate, dopamine and acetylcholine) in both human and rodent assays [24, 25]. More specifically, $\mathrm{CB} 1$ activation has been shown to inhibit AC activity and thereby cAMP production [26], similar to the action of triptans. In addition to activation of $\mathrm{G}_{\mathrm{i} / \mathrm{o}}$-coupled $\mathrm{CB} 1$ receptors, cannabinoids have also been shown to stimulate $\mathrm{G}_{\mathrm{q} / 11}$-coupled $\mathrm{CB} 1$ receptors, highlighting the complexity of cannabinoid signalling [27].

Previous studies have shown that anandamide, the endogenous non-selective cannabinoid receptor agonist, is able to inhibit trigeminovascular dilation, $\mathrm{C}$ - and A $\delta$-fibre activity as well as transient receptor potential ankyrin 1 (TRPA1) and transient receptor potential vanilloid 1 (TRPV1)-mediated CGRP release [28-31]. At higher concentrations, anandamide has also been shown to stimulate CGRP release through activation of TRPV1 [31]. The TRPV1 receptor, also known as the capsaicin receptor, has been demonstrated to colocalize with CGRP, substance P (SP) and nitric oxide (NO) in the human TG [32]. In a previous study by Fischer et al., it was examined whether methanandamide (mAEA), a synthetic anandamide analogue, modulates heat-induced CGRP release in the dura. mAEA was found to either depress (at non-noxious temperatures) or facilitate (at noxious temperatures) heat-induced CGRP release, indicating opposing dual actions of eCBs on CGRP release in the dura [33]. Since heat specifically activates TRPV1, one may ask whether eCBs exert the same dual effects on CGRP release when more general mechanisms, such as cellular depolarization, are employed to stimulate release. 
Using the rat hemi-skull model, this study aims to determine the effect of arachidonyl-2'-chloroethylamide (ACEA), a synthetic anandamide analogue with high potency and selectivity for $\mathrm{CB} 1$ [34], on $\mathrm{K}^{+}$- and capsaicin-induced CGRP release from the dura and TG of male Sprague-Dawley rats. In addition, we examine the expression of CB1, CB2, receptor activity modifying protein 1 (RAMP1) and CGRP in the TG utilizing IHC.

\section{Methods}

\section{Animals}

Sprague-Dawley rats $(300-400 \mathrm{~g})$ purchased from Taconic (Ejby, Denmark) were maintained on a $12 / 12 \mathrm{~h}$ light/dark cycle (with dark beginning at $7 \mathrm{am}$ ) and housed at constant temperature $\left(22 \pm 2^{\circ} \mathrm{C}\right)$ and humidity $(55 \pm 10 \%)$, with free access to food and water. Rats were generally housed in Eurostandard cages (Type VI with 123-Lid) 2-6 together.

\section{In situ/in vitro CGRP release}

Rats were anaesthetized by $\mathrm{CO}_{2}$ inhalation and decapitated. All procedures are approved by the Danish Animal Experimentation Inspectorate. The protocol is described in detail elsewhere [35]. Following decapitation and removal of skin, skulls were immersed in synthetic interstitial fluid kept on ice to maintain metabolism at low levels. Skulls were cut mid-sagittally and brains were removed whilst the cranial dura and TGs were left attached to the hemi-skulls. The TGs were subsequently dissected from the hemi-skulls and transferred to polypropylene tubes containing $10 \mathrm{~mL}$ synthetic interstitial fluid (SIF) and kept in a water bath at $+37^{\circ} \mathrm{C}$ for $30 \mathrm{~min}$. Hemi-skulls were transferred to beakers containing SIF and placed in a water bath at $+37^{\circ} \mathrm{C}$ for $15 \mathrm{~min}$ and then washed twice with intervals of $15 \mathrm{~min}$ by renewing the SIF solution.

TGs were randomized, placed in Eppendorf tubes on a heating block from Eppendorf (Hamburg, Germany) at $+37^{\circ} \mathrm{C}$, and washed five times with $300 \mu \mathrm{L}$ SIF with intervals of $10 \mathrm{~min}$. Hemi-skulls were randomized, placed on polystyrene cell culture plates from Sarstedt (Europe) in a water bath from Memmert (Bayern, Germany) at $+37^{\circ} \mathrm{C}$ and washed five times with $300 \mu \mathrm{L}$ SIF with intervals of $10 \mathrm{~min}$. After the last $10 \mathrm{~min}$ incubation with $300 \mu \mathrm{L}$ SIF, $200 \mu \mathrm{L}$ samples (measuring baseline CGRP release) were extracted from the dura and TG and placed in Eppendorf tubes. The described procedures (i.e., washing and baseline extraction) were performed in all experiments prior to incubation with test compounds. It was previously demonstrated by Bhatt et al. that there is no significant difference between left and right CGRP release from the dura and TG [35], thus in the present experiments, one side functioned as a control for the other. In each experiment, one side was used for vehicle application, whereas the other was used to examine the effect of ACEA/AMG9810.

\section{ELISA}

To measure the amount of CGRP release from both tissues (dura and TG), samples were processed using commercial CGRP (human) Enzyme Immunoassay (EIA) kits from SPIbio (Paris, France). The antibody in the EIA kit is meant for human CGRP but has $100 \%$ cross reactivity with rat CGRP [5] and was therefore utilized in this experiment. $50 \mu \mathrm{L}$ EIA buffer was added to each of the $200 \mu \mathrm{L}$ samples as well as to the CGRP standards. EIA buffer contains protease inhibitors and prevents CGRP degradation [5]. The CGRP tissue concentrations were determined based on the standard curve. The experiments were performed following the manufacturer's protocol. Optical density was determined at $410 \mathrm{~nm}$ using a micro-plate photometer (Tecan, Infinite M200) and software from Magellan, version v.6.3 (Männedorf, Switzerland). Data was exported to Excel for analysis.

\section{Synthetic interstitial fluid}

SIF was made using distilled water and was of the following composition (in $\mathrm{mM}$ ): $\mathrm{NaCl} 108, \mathrm{KCl} 3.48, \mathrm{MgSO}_{4}$ 3.5, $\mathrm{NaHCO}_{3} 26, \mathrm{NaH}_{2} \mathrm{PO}_{4}$ 11.7, $\mathrm{CaCl}_{2} 1.5, \mathrm{Na}^{+}$Gluconate 9.6, Glucose 5.55 and Sucrose 7.6. For $\mathrm{K}^{+}$-induced nerve fibre stimulation, a second SIF solution was prepared in which the $\mathrm{KCl}$ concentration was increased to $60 \mathrm{mM}$. To maintain similar osmolarities in the two solutions, the $\mathrm{NaCl}$ concentration was reduced appropriately. $\mathrm{NaCl}, \mathrm{NaH}_{2} \mathrm{PO}_{4}$ and $\mathrm{CaCl}_{2}$ were supplied from EMSURE (Darmstadt, Germany) and the rest from Sigma-Aldrich (Darmstadt, Germany). All solutions were bubbled with $95 \% \mathrm{O}_{2}$ and $5 \% \mathrm{CO}_{2}$.

\section{Immunohistochemistry}

Adult, male Sprague-Dawley rats were anaesthetized by $\mathrm{CO}_{2}$ inhalation and decapitated. TGs were carefully dissected and fixated with $4 \%$ paraformaldehyde (Sigma, St Louis, USA) diluted in phosphate buffered saline (PBS) for $2-4 \mathrm{~h}$. To ensure cryoprotection the fixated TGs were submerged in a $10 \%$ sucrose in Sorensen's phosphate buffer ( $\mathrm{pH} 7.2)$ at $+4{ }^{\circ} \mathrm{C}$ for $3-4 \mathrm{~h}$. Subsequently, the TGs were submerged in a $25 \%$ sucrose in Sorensen's phosphate buffer $(\mathrm{pH} 7.2)$ at $+4{ }^{\circ} \mathrm{C}$ overnight. The following day, the TGs were embedded in a gelatine medium $(30 \%$ egg albumin, $3 \%$ gelatine) and stored at $-20^{\circ} \mathrm{C}$. The TGs were then sectioned at $10 \mu \mathrm{m}$, collected on microscope slides (Superfrost, ThermoFisher) and stored at $-20^{\circ} \mathrm{C}$ until used.

TG sections were thawed at room temperature (RT) and subsequently washed in PBS containing 0.25\% 
Triton-X (PBS-T) for $2 \times 15$ minutes. A primary antibody was applied to each sample and the slides were incubated overnight at $+4{ }^{\circ} \mathrm{C}$ in moisturized incubation chambers. The following day, the sections were washed with PBS-T $2 \times 15$ minutes prior to incubation with secondary antibodies for $1 \mathrm{~h}$ at RT. Finally, the sections were washed $2 \times 15$ minutes and a coverglass was mounted with Vectashield mounting medium containing 4',6-diamidino-2-phenylindole (DAPI) (Vector Laboratories, Burlingame CA, USA). The antibodies used and concentrations are given in Table 1.

For double IHC, the procedure was repeated twice before mounting. Negative controls (Supplementary Fig. 1) were performed by omitting the primary antibody. Any resulting immunofluorescence would suggest unspecific binding of the secondary antibodies or insufficient washing. The sections were examined in a light and epifluorescence microscope (Nikon 80i, Tokyo, Japan) equipped with a Nikon DS-2MV camera. Lastly, figure montages were processed in Adobe Photoshop CC20 (Adobe Systems, Mountain View, CA, USA).

\section{Compounds}

ACEA, supplied pre-dissolved in anhydrous ethanol $(5 \mathrm{mg} / \mathrm{mL}, 13.66 \mathrm{mM})$, was purchased from Tocris (Bristol, UK). Ethanol was used as vehicle for ACEA throughout all experiments and did not exceed $0.001 \%$. Capsaicin was supplied from Tocris (Bristol, UK), dissolved in a $10 \mathrm{mM}$ stock solution in $100 \%$ ethanol and was further diluted to a $0.001 \%$ ethanol containing solution of $100 \mathrm{nM}$ capsaicin. AMG9810 was supplied from Tocris (Bristol, UK) and was dissolved at $1 \mathrm{mM}$ in a $10 \%$ ethanol and $90 \%$ DMSO containing solution, which was also used as vehicle. When diluted the concentration of ethanol and DMSO was $0.01 \%$ and $0.09 \%$, respectively. All remaining compounds were purchased from Sigma Aldrich/Merck (Darmstadt, Germany).

\section{Statistics}

All data was subject to Grubb's test $(\alpha=0.05)$ which was performed using the GraphPad outlier calculator. All the CGRP and Substance P release data passed the ShapiroWilk normality test $(\alpha=0.05)$. Further, all identified outliers were removed from the dataset prior to performing Student's T-test and calculating mean and SEM values. Data for CGRP release is shown with mean \pm SEM, where ' $n$ ' represents the sample size (i.e., number of animals).

\section{Results \\ CGRP release}

It has been well established in both human and rodent assays that $\mathrm{G}_{\mathrm{i} / \mathrm{o}^{-}}$-coupled $\mathrm{CB} 1$ receptors are involved in retrograde suppression of neurotransmitter release [24, 25]. Since ACEA is a potent and highly selective CB1 agonist [34], we sought to examine the therapeutic potential of ACEA in migraine pathology by investigating whether ACEA per se, affects CGRP levels in the dura and TG of male Sprague-Dawley rats.

$140 \mathrm{nM}$ ACEA per se caused a significant increase in CGRP release from the dura (w/o ACEA: $10.3 \pm 2.2 \mathrm{pg} /$ $\mathrm{mL}$; $/$ ACEA: $15.0 \pm 2.8 \mathrm{pg} / \mathrm{mL} ; p=0.008, n=8)$ compared to vehicle (Fig. 1A-B). In the TG however, the difference was non-significant (w/o ACEA: $53.3 \pm 10.1 \mathrm{pg} /$ $\mathrm{mL} ; \quad$ w/ACEA: $\quad 37.9 \pm 7.1 \mathrm{pg} / \mathrm{mL}, \quad p=0.08, \quad n=12$ ) (Fig. 1C-D). In continuation, we performed an experiment in which $100 \mathrm{nM}$ capsaicin was used as a TRPV1specific stimulus (Fig. 1). 140 nM ACEA did not cause significant inhibition of capsaicin-induced CGRP release in the TG (w/o ACEA: $127.2 \pm 22.1 \mathrm{pg} / \mathrm{mL} ; \mathrm{w} / \mathrm{ACEA}$ : $124.6 \pm 16.9 \mathrm{pg} / \mathrm{mL}, p=0.72, n=12$ ) or dura (w/o ACEA: $51.7 \pm 13.3 \mathrm{pg} / \mathrm{mL} ; \mathrm{w} / \mathrm{ACEA}: 49.4 \pm 8.2 \mathrm{pg} / \mathrm{mL}, p=0.43$, $n=8$ ) (Fig. 1). Considering that ACEA is the synthetic analogue of anandamide, which has been shown to stimulate CGRP release through activation of TRPV1 [31], it is possible that ACEA stimulated CGRP release through a higher degree of TRPV1 than CB1 activation.

Due to the potential implication of TRPV1 in CGRP release, we performed another experiment in which

Table 1 Primary and secondary antibodies used

\begin{tabular}{llllll}
\hline Product & Code & Source & Dilution & Immunogen & Company \\
CB1 & ACR-001 & Rabbit & 1:100 & N-terminal of rat CB1 receptor & Alomone Labs, Jerusalem, Israel \\
CB2 & ACR-002 & Rabbit & $1: 100$ & 3rd intracellular loop of rat CB2 receptor & Alomone Labs, Jerusalem, Israel \\
CGRP & Ab81887 & Mouse & 1:100 & Rat a-CGRP & Abcam, Cambridge, UK \\
RAMP1 & 844 & Goat & 1:100 & C-terminal of human RAMP1 & Merck \& Co., Inc., West Point, PA, USA \\
Product & & Source & Dilution & Against & Company \\
FITC & Goat & 1:100 & Anti-rabbit & Cayman Chemical, Ann Arbor, MI, USA \\
Alexa 594 & Goat & 1:100 & Anti-mouse & Jackson Immunoresearch Laboratories, Inc., West Grove, PA, USA \\
Cy3 & Donkey & 1:200 & Anti-goat & Jackson Immunoresearch Laboratories, Inc., West Grove, PA, USA \\
\hline
\end{tabular}




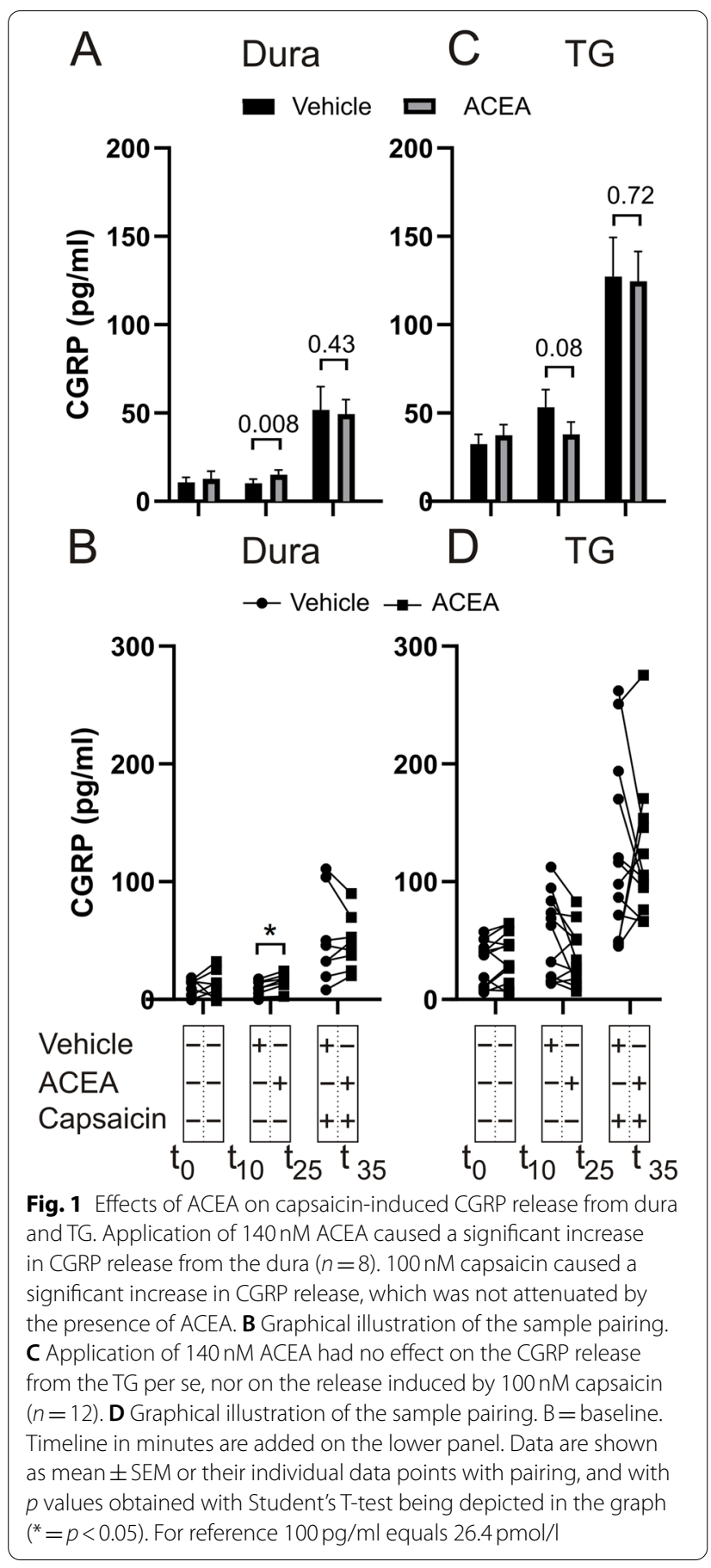

$60 \mathrm{mMK}^{+}$was used as depolarizing stimulus. Addition of $140 \mathrm{nM}$ ACEA per se showed a slight but similar tendency to stimulate CGRP release in the dura (w/o ACEA: $19.4 \pm 3.7 \mathrm{pg} / \mathrm{mL} ; \quad$ w $/$ ACEA: $21.2 \pm 4.0 \mathrm{pg} / \mathrm{mL}, p=0.28$, $n=12)$ as well as in the TG (w/o ACEA: $28.6 \pm 5.9 \mathrm{pg} / \mathrm{mL}$; w/ACEA: $31.7 \pm 6.4 \mathrm{pg} / \mathrm{mL}, p=0.42, n=9)$ compared to vehicle (Fig. 2). Further, due to the difference observed

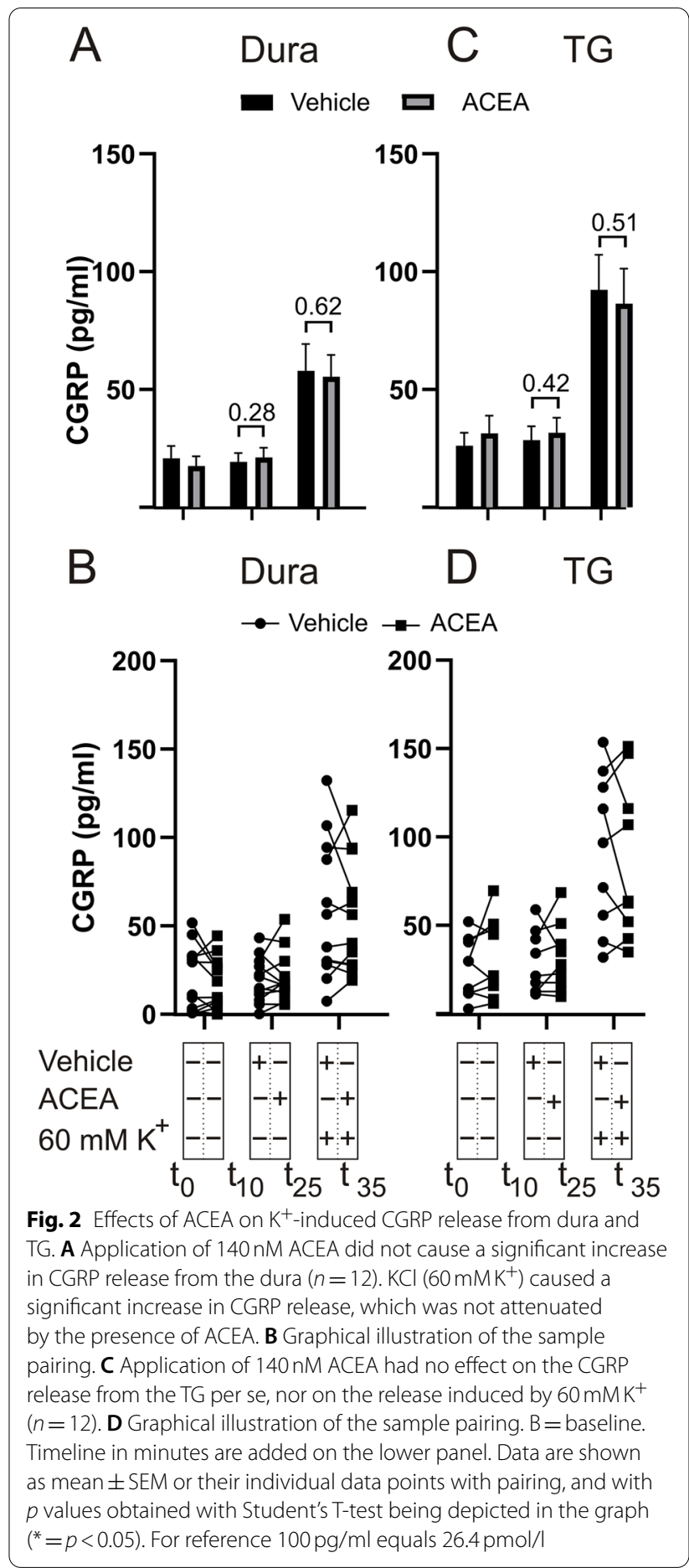

in these experiments, we combined all data after adding ACEA and compared to vehicle. The direct effect of adding ACEA per se was a change from baseline of $4.1 \pm 1.9 \mathrm{pg} / \mathrm{mL}$ compared to vehicle at $-0.7 \pm 1.7 \mathrm{pg} /$ $\mathrm{mL}$ being significant $(p=0.023, n=20)$. When we further tested whether the addition of $140 \mathrm{nM}$ ACEA would 
affect $\mathrm{K}^{+}$-induced CGRP release, no significant inhibition was observed in the dura (Fig. 2A-B) or TG (Fig. 2C-D).

Since no significant inhibition was observed using $\mathrm{K}^{+}$as depolarizing stimulus, it was considered whether TRPV1 competes with CB1 for binding to ACEA. Therefore, we performed an experiment using AMG9810, a potent and selective, competitive antagonist of TRPV1. Upon $\mathrm{K}^{+}$-stimulation in the presence of $1 \mathrm{mM}$ AMG9810, $140 \mathrm{nM}$ ACEA demonstrated significant inhibition of CGRP release in the dura (w/o AMG9810: 60.5 $\pm 5.1 \mathrm{pg} /$ $\mathrm{mL} ; \mathrm{w} / \mathrm{AMG} 9810: 47.2 \pm 4.1 \mathrm{pg} / \mathrm{mL}, p=0.011, n=12$ ) (Fig. 3A-B) and TG (w/o AMG9810: $117.7 \pm 9.6 \mathrm{pg} / \mathrm{mL}$; w/AMG9810: $86.6 \pm 10.6 \mathrm{pg} / \mathrm{mL}, p=0.04, n=9$ ) (Fig. 3CD) compared to ACEA w/o AMG9810.

\section{Immunohistochemistry}

IHC images were used to determine the cellular location of CB1, CB2, CGRP and RAMP1 in the TG. RAMP1 is an essential part of the functional CGRP receptor [36] and therefore represents potential localization of the CGRP receptor, although it could also label neurons with the Amylin 1 receptor [37]. Nevertheless, Fig. 4 shows a high expression level of CB1 in neuronal somas of the TG relative to that observed in satellite glial cells (SGCs) and neuronal fibres. In contrast, CGRP was highly expressed in C-fibres with limited localization to neuronal somas of the TG (Fig. 4A), whereas RAMP1 exhibited high expression levels in both $A \delta$-fibres and neuronal somas (Fig. 4B). Furthermore, CB1 was found to colocalize with CGRP in neuronal somas, whereas colocalization in the CGRP associated C-fibres was not clearly detected (Fig. 4A). Colocalization of CB1 and RAMP1 was observed in neuronal somas and $A \delta$-fibres of the TG (Fig. 4B).

CB2 was found to be highly expressed in many SGCs relative to that observed in neuronal somas and fibres of the TG (Fig. 5). In addition, CB2 did not demonstrate colocalization with neither CGRP (Fig. 5A) nor RAMP1 (Fig. 5B) in the TG, supporting the notion that ACEA exerts its effect through CB1, and not CB2.

\section{Discussion}

The data presented in the present study shows that the cannabinoid system in the TVS must be seen in light of TRPV1 crosstalk. CB1 activation is able to reduce CGRP release, but only when TRPV1 is blocked. This adds to the notion that receptors which couple negatively through cAMP have antimigraine potential, but off target effects could hide such responses.

IHC results from the TG revealed abundant expression of CB1 in neuronal somas, and to a lesser extent in $\mathrm{C}$ - and $\mathrm{A} \delta$-fibres (Fig. 4). In addition, IHC results showed

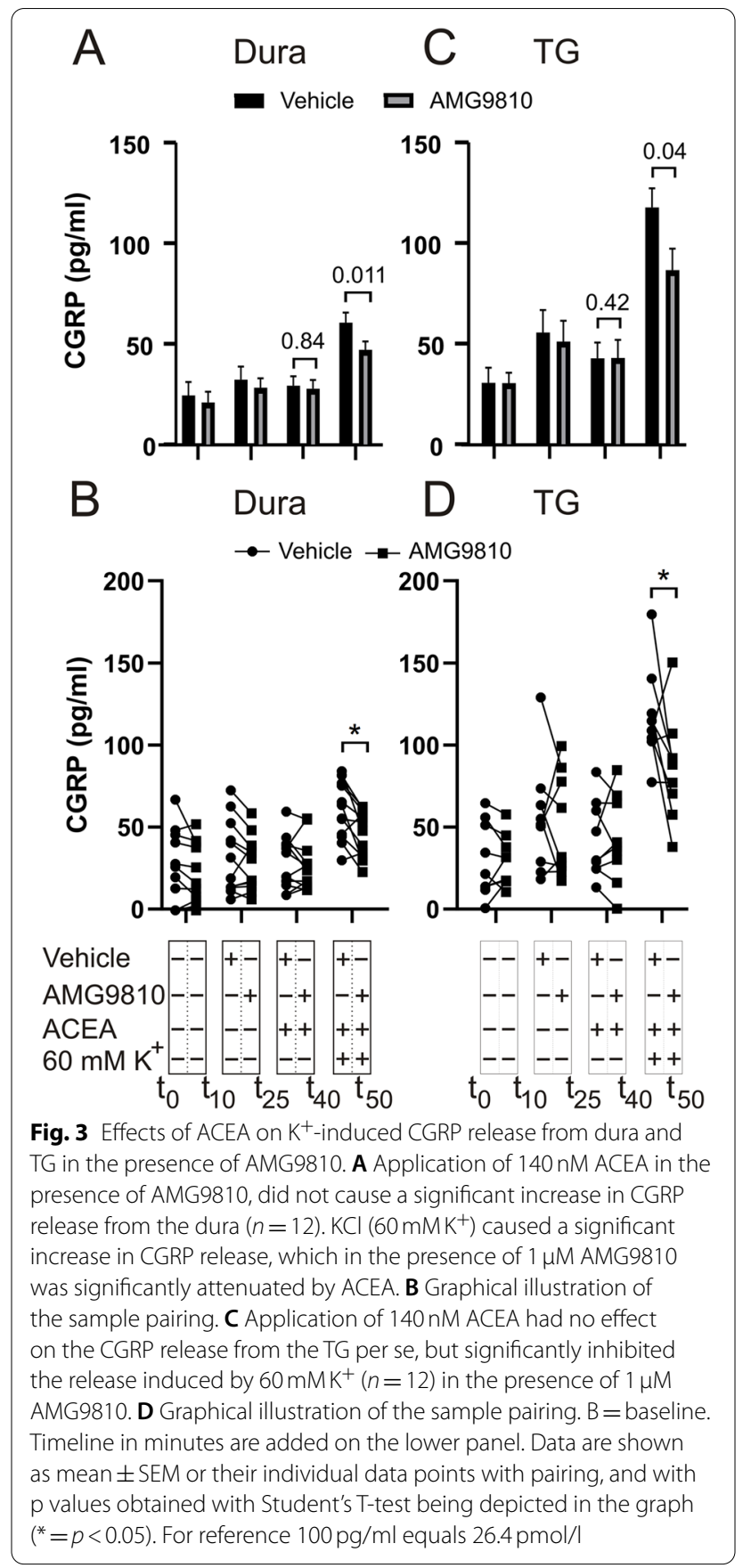

colocalization of CB1 with CGRP and RAMP1 (an indicator of CGRP receptor expression) in neuronal somas and to some extent in fibres of the TG, supporting the notion that CB1 may act through retrograde feedback inhibition of CGRP. We cannot rule out a possible interaction with neurons containing the Amylin 1 receptors, which has been detected in TG [38, 39]. Our findings are in agreement with those of Price et al. which demonstrate predominant colocalization of $\mathrm{CB} 1$ with markers 

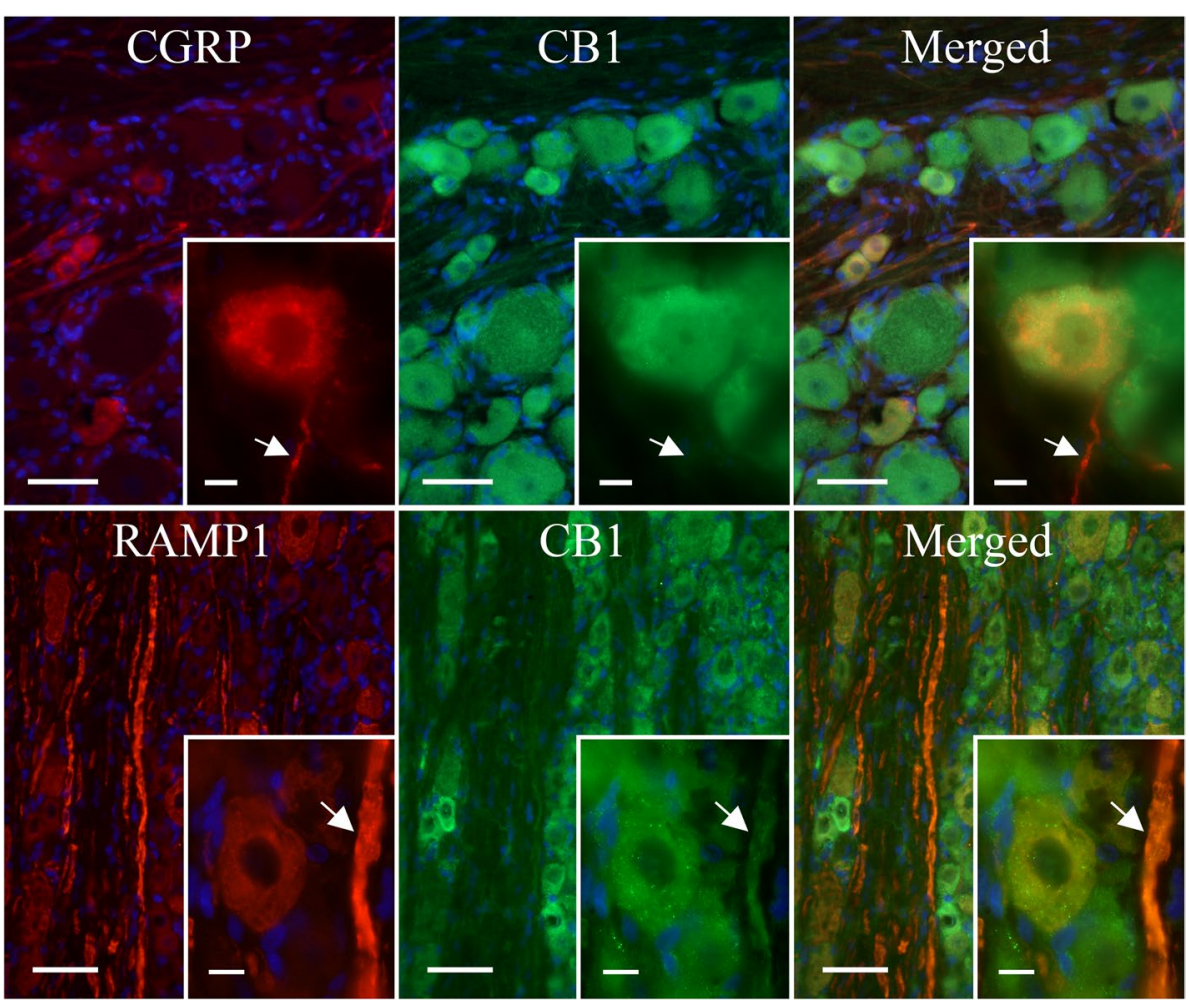

Fig. 4 The expression of CB1, CGRP and RAMP1 in the TG. IHC localization of CB1, CGRP and the functional CGRP receptor (by staining for RAMP1) in the TG. Blue represents cell nuclei; orange represents colocalization of CGRP (upper panel) or RAMP1 (lower panel) with CB1; globular regions represent neuronal somas and fibrous regions represent individual neuronal fibres. Large image scale corresponds to $50 \mathrm{~mm}$, and the insert scale corresponds to $10 \mu \mathrm{m}$. The arrows mark unmyelinated C-fibres (upper panel) and myelinated A $\delta$-fibres (lower panel)

for myelinated large diameter fibres in the TG, and to a lesser extent with CGRP containing small diameter fibres [40]. In addition, Price et al. show that CB1 rarely colocalizes with TRPV1 in the TG [40], suggesting that CB1 and TRPV1 do not act in a concerted manner, but rather as part of two distinct systems both governing modulation of nociception and CGRP signalling.

Looking at expression data of the receptors, we reanalysed previously published data that was constructed using publicly available sequencing data generated by Hougaard Pedersen and collaborators [41]. RNA counts are depicted relative to $5-\mathrm{HT}_{1 \mathrm{~B}}$, since $5-\mathrm{HT}_{1 \mathrm{~B}}$ agonists are the gold standard in migraine treatment and have shown to effectively inhibit cAMP production and CGRP release [17]. As can be seen in Supplementary Fig. 2 the average $\mathrm{CB} 1$ expression level is considerably higher than that of $5-\mathrm{HT}_{1 \mathrm{~B} / 1 \mathrm{D}}$, CB2 expression only constitutes approximately $10 \%$ of $5-\mathrm{HT}_{1 \mathrm{~B} / 1 \mathrm{D}}$ expression. Furthermore, it was observed that TRPV1 is expressed almost double that of CB1 in the TG, roughly corresponding to an expression level 10 times that of $5-\mathrm{HT}_{1 \mathrm{~B} / 1 \mathrm{D}}$.

The initial application of ACEA demonstrated a significant increase in CGRP release from the dura, whereas the response from the TG was non-significant. Although ACEA is a relatively specific agonist of CB1, it has been shown to activate TRPV1 [42]. When AMG9810, a blocker of TRPV1, was added (Fig. 3) there was no CGRP release caused by ACEA, suggesting that the effect was mediated by TRPV1 activation. This indicates that the slight tendency of ACEA to augment the capsaicininduced response was caused by additional activation of TRPV1, and that the postulated ACEA-mediated CB1 activation did not constitute the main effect. The nonsignificant response observed in the TG upon ACEA application may be explained by the dual action of ACEA acting on $\mathrm{G}_{\mathrm{i} / \mathrm{o}}$-coupled $\mathrm{CB} 1$ receptors as well as on TRPV1 to inhibit and stimulate CGRP release, respectively, leading to a balanced response (Fig. 6).

When using $\mathrm{K}^{+}$-induced depolarization as stimulation, we hypothesized that CB1 activation and subsequent inhibition of CGRP release would be the predominant pathway. This was based on the earlier notion that anandamide is able to inhibit $\mathrm{K}^{+}$(and capsaicin)-induced CGRP release [43]. However, no significant inhibition was observed in this setting, although a tendency of inhibition was seen in the TG (Fig. 2). There is contrasting 

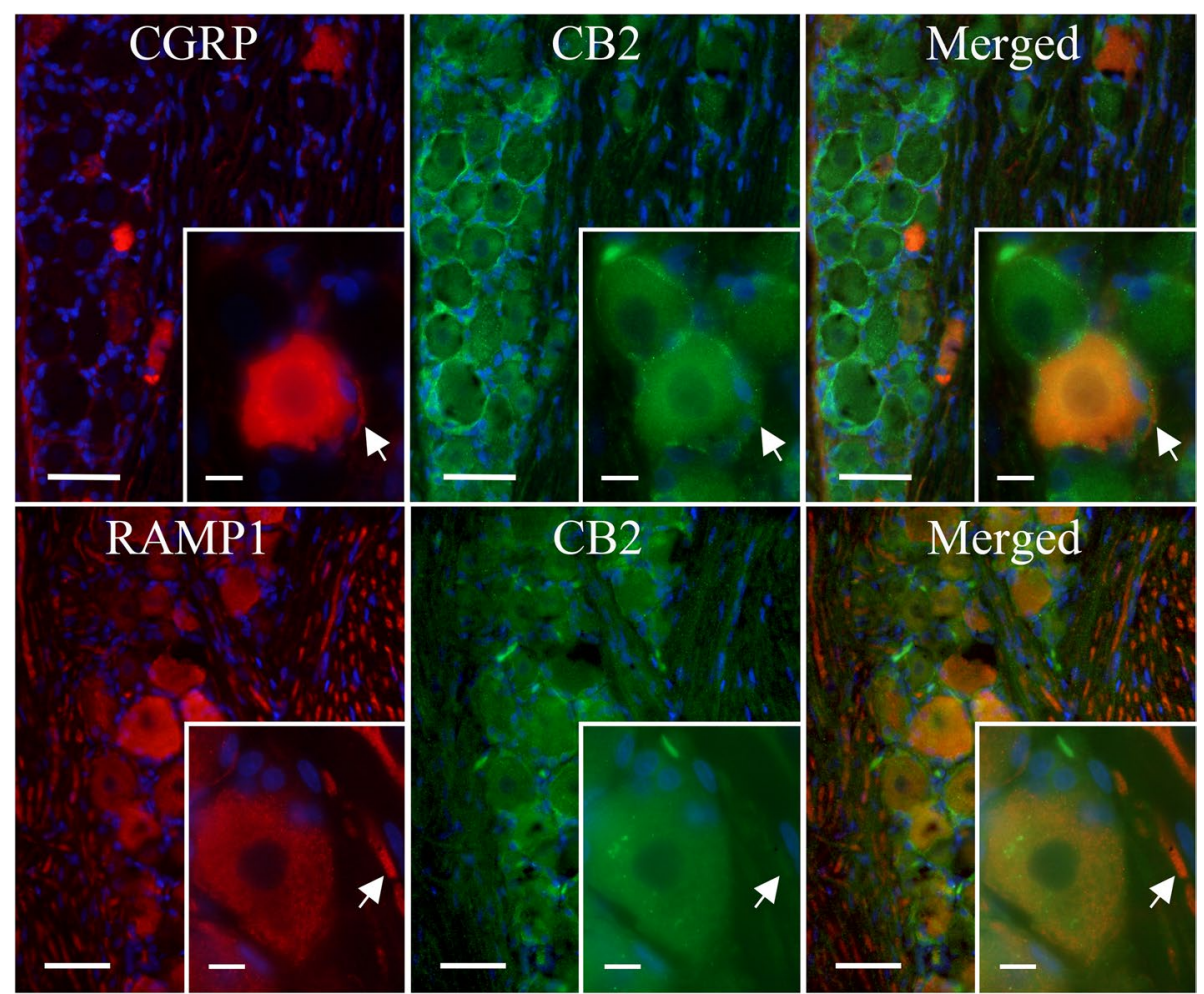

Fig. 5 The expression of CB2, CGRP and RAMP1 in the TG. IHC localization of CB2, CGRP and the functional CGRP receptor (by staining for RAMP1) in the TG. Blue represents cell nuclei; orange represents colocalization of CGRP (upper panel) or RAMP1 (lower panel) with CB2; globular regions represent neuronal somas and fibrous regions represent individual neuronal fibres. Large image scale corresponds to $50 \mathrm{~mm}$, and the insert scale corresponds to $10 \mu \mathrm{m}$. The arrows mark unmyelinated C-fibres (upper panel) and myelinated A $\delta$-fibres (lower panel)
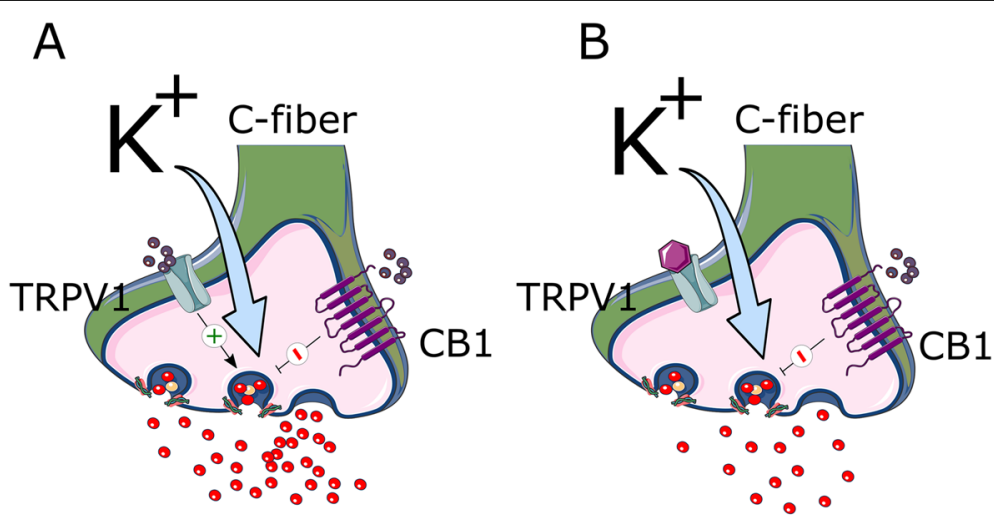

\section{:CGRP : ACEA DAMG9810}

Fig. 6 Graphical illustration of the interaction of CB1 and TRPV1 by cannabinoids. A ACEA activates both TRPV1 and CB1 in a native setting, leading to no observed inhibition. $\mathbf{B}$ when TRPV1 is inhibited, activation of CB1 leads to an attenuation of the CGRP release

evidence from previous studies of the involvement of CB1 in CGRP release, particularly in relation to TRPV1 activation. This leads to a discussion of the interaction between the cannabinoid and TRPV1 systems. Several arachidonic acid metabolites, including anandamide, are viewed as putative endogenous TRPV1 ligands, termed endovanilloids [44]. Interestingly, many of the transient receptor potential (TRP) channels have been considered 
"ionotropic cannabinoid receptors" [45], and anandamide has been shown to stimulate CGRP release through additional activation of TRPV1 [31]. Somewhat paradoxical, eCBs would therefore be able to: i) stimulate CGRP release through activation of TRPV1, and ii) inhibit CGRP release through activation of $\mathrm{G}_{\mathrm{i} / \mathrm{o}}$-coupled CB1 receptors or by homologous and heterologous desensitization of TRPV1 and TRPA1, respectively [30, 31]. Indeed, Akerman and colleagues have suggested that in the TCC or TNC, anandamide inhibits neurons with C-fibre input through activation of CB1, an inhibition which is increased after blockade of TRPV1, [29] and Messlinger and colleagues have indicated opposing dual actions of eCBs on CGRP release in the dura [33]. This contrasts with the actions of anandamide in the periphery where the primary effect is postsynaptic inhibition of dural blood vessel dilatation, and only partial inhibition of CGRP release [28]. Current knowledge on how and which cannabinoids target TRP channels is still scarce [46]. It appears that ACEA adds to the eCB analogues that previously have been shown to activate TRPV1 [47], and in our setup can cause CGRP release.

In comparison to other systems, several neurons in the dorsal periaqueductal grey (dPAG) co-express CB1 and TRPV1, making it possible that an endogenous substance, i.e., anandamide, may exert both panicolytic and panicogenic effects via its actions at CB1 and TRPV1, respectively [48]. It has been postulated by Tognetto and colleagues that lower anandamide levels could act mainly on CB1, whereas TRPV1-mediated actions may prevail over CB1 at higher concentrations [49]. We are therefore not the first to suggest that if large amounts of endogenous anandamide could be produced, that could activate, rather than inhibit, nociceptive sensory neurons [49]. In support of this, it has previously been shown that anandamide application results in excitation of peripheral terminals of capsaicin-sensitive primary sensory neurons via cannabinoid receptor independent mechanisms, most likely TRPV1 activation, and causes CGRP release [50]. Further, Tognetto and colleagues showed that application of higher concentrations of anandamide to capsaicinsensitive dorsal root ganglia (DRG) neurons leads to neuropeptide release [49]. It has long been known that the endogenous ligand anandamide behaves as an agonist of TRPV1 [51]. One major contrast between the cannabinoid- and capsaicin-evoked currents for TRPV1 is the lack of apparent pore dilation (a characteristic of a two state channel) in response to cannabinoids, even when large currents are driven by high doses of cannabinoids or long induction times [52]. However, the in vivo effects of this are not well understood. Interestingly, this cross activation of TRPV1 also seems to apply to the more CB1-specific ACEA, as we in the current study were not able to find a window of pure inhibition per se. Thus, we conclude that cannabinoid signalling in the TG shows similarities to other systems and appears to be complexly regulated.

What effect does CB1 activation exert when TRPV1 is blocked? AMG9810, which is a potent and competitive TRPV1-selective antagonist [53], was administered prior to ACEA in order to determine whether the ACEAinduced increase in CGRP levels without stimulation was a result of TRPV1 activation. Unlike capsazepine, which only inhibits the capsaicin-induced $\mathrm{Ca}^{2+}$ influx, AMG9810 inhibits capsaicin-, proton-, heat- and endogenous agonist-induced activation of TRPV1 [53], thus presenting a broader spectrum of inhibition. When TRPV1 was blocked, CB1 activation had inhibitory effects both in the dura and in the TG (Fig. 6). It has been well established in both human and rodent assays that $G_{i / 0}$-coupled $\mathrm{CB} 1$ receptors are involved in retrograde suppression of neurotransmitter release $[24,25]$. We therefore conclude that CB1 activation leading to cannabinoid-mediated inhibition of CGRP release only occurs when TRPV1 is blocked. This supports the findings by Akerman et al., in which anandamide inhibited A-fibre inputs to the TCC only in the presence of capsazepine [29], as well as the findings by Fischer et al., showing the dual actions of eCBs on heat activated CGRP release [33], highlighting the dual agonistic properties of cannabinoids throughout the TVS and with various stimuli.

In the current context, a study by Summ et al. demonstrated that application of TRPV1 antagonist A-993610 did not per se inhibit $C$ - and A $\delta$-fibre activity in the TCC in response to electrical stimulation of the middle meningeal artery or after spreading depression [54]. Therefore it does not appear that TRPV1 antagonism in itself is a sufficient migraine target, but the data presented here show that it could potentially be combined with other drugs targeting the eCB system. Finding the right dose combination, which stimulates $\mathrm{CB} 1$ without activating TRPV1, would need more complex pharmacokinetics. Nevertheless, our study confirms and further support the hypotheses $[10,55]$ that receptors which lower the cAMP levels are potential pharmacological targets for treating migraine. Our study highlights the need to preclinically test for any off-target effects.

\section{Conclusion}

In conclusion, application of ACEA alone significantly stimulated CGRP release from the dura, indicating that ACEA does not exhibit antimigraine potential, at least based on data from the current setup. Cannabinoid signalling pathways appear to be very complex with many factors, such as functional selectivity, agonist concentration and regional differences in protein distribution, 
capable of modulating the response. We show that CB1 could have antimigraine potential when TRPV1 is blocked, but that the clinical applicability of this finding might be limited. Although the physiological activation of TRPV1 most likely is heat activation, we suggest that future studies should consider that TRPV1 channel activation could be due to a pathological response during overactive cannabinoid signalling.

\begin{abstract}
Abbreviations
ADP: Adenosine Diphosphate; AC: Adenylate Cyclase; Anandamide: $\mathrm{N}$-arachidonoylethanolamine; ACEA: Arachidonyl-2'-chloroethylamide; CGRP: Calcitonin Gene-Related Peptide; CB1: Cannabinoid Receptor Type 1; CB2: Cannabinoid Receptor Type 2; CAMP: Cyclic Adenosine Monophosphate; CNS: Central Nervous System; dPAG: Dorsal Periaqueductal Gray; DRG: Dorsal Root Ganglia; eCB: Endocannabinoid; ECS: Endocannabinoid system; ELISA: Enzyme-Linked Immunosorbent Assay; GPCR: G-Protein Coupled Receptor; GTN: Nitro-glycerine; IHC: Immunohistochemistry; MMA: Middle Meningeal Artery; NO: Nitric Oxide; PBS: Phosphate Buffered Saline; PNS: Peripheral Nervous system; RAMP1: Receptor Activity Modifying Protein 1; RT: Room Temperature; SGC: Satellite Glial Cell; SIF: Synthetic Interstitial Fluid; SP: Substance P; TRP: Transient Receptor Potential; TRPA1: Transient Receptor Potential Ankyrin 1; TRPV1: Transient Receptor Potential Vanilloid 1; TG: Trigeminal Ganglion; TNC: Trigeminal Nucleus Caudalis; TCC: Trigeminocervical Complex; TVS: Trigeminovascular System; TRP: Transient Receptor Potential; 2-AG: 2-arachidonoylglycerol; 5-HT: 5-hydroxytryptamine.
\end{abstract}

\section{Supplementary Information}

The online version contains supplementary material available at https://doi. org/10.1186/s10194-022-01399-8.

Additional file 1: Supplementary Fig. 1. Negative control for CB1 and CB2. The negative control for the FITC antibody used for CB1 and CB2 IHC.

Additional file 2: Supplementary Fig. 2. mRNA expression in the trigeminal ganglion. The average RNA counts of 10 rats in the TG. RNA counts are depicted on a logarithmic scale relative to $5-\mathrm{HT}_{1 \mathrm{~B}}$ and are shown for $5-\mathrm{HT}_{1 \mathrm{~B}} ; 5-\mathrm{HT}_{1 \mathrm{D}}$; $\mathrm{CB} 1$; CB2; TRPV1; RAMP1 and CGRP.

\section{Acknowledgements}

Not applicable.

\section{Authors' contributions}

IMC and KAH designed the study; IMC, JCAE, PVR and KAH performed experiments; LE provided tools and reagents; IMC, JCAE, PVR, LE and KAH analysed the data; IMC and KAH wrote the manuscript; JCAE, PVR and LE made further critical manuscript revisions. All authors read and commented on the final manuscript. The authors read and approved the final manuscript.

\section{Funding}

KAH and PVR was supported by a Lundbeck foundation Fellowship (R3452020-1977) and a research grant from the International Headache Society. The funders had no role in study design, data collection and analysis, decision to publish, or preparation of the manuscript.

\section{Availability of data and materials}

The datasets generated during and/or analysed during the current study are available from the corresponding author on reasonable request.

\section{Declarations}

\section{Ethics approval and consent to participate}

The animal part of the study followed the guidelines of the European Communities Council (86/609/ECC) and was approved by the Regional Ethical
Committee on Animal Research, Malmö/Lund, Sweden (M43-07) and by an auspices of the Swedish Department of Agriculture (M8-09, M126-12) and the Danish Animal Experimentation Inspectorate. All animal experiments were therefore performed in accordance with the European Community Council Directive on 'The Protection of Animals Used for Scientific Purposes' (2010/63/EU).

\section{Consent for publication}

Not applicable.

\section{Competing interests}

The authors declare no potential conflicts of interest with respect to the research, authorship, and/or publication of this article.

\section{Author details}

${ }^{1}$ Department of Clinical Experimental Research, Glostrup Research Institute, Rigshospitalet, Glostrup, Denmark. ${ }^{2}$ Department of Biology, University of Copenhagen, Copenhagen, Denmark. ${ }^{3}$ Department of Drug Design and Pharmacology, Faculty of Health and Medical Sciences, University of Copenhagen, Copenhagen, Denmark. ${ }^{4}$ Department of Medicine, Institute of Clinical Sciences, Lund University, Lund, Sweden.

Received: 14 December 2021 Accepted: 4 February 2022

Published online: 21 February 2022

\section{References}

1. Goadsby PJ, Edvinsson L, Ekman R (1990) Vasoactive peptide release in the extracerebral circulation of humans during migraine headache. Ann Neurol 28(2):183-187

2. Ebersberger A, Averbeck B, Messlinger K, Reeh PW (1999) Release of substance $\mathrm{P}$, calcitonin gene-related peptide and prostaglandin E2 from rat dura mater encephali following electrical and chemical stimulation in vitro. Neuroscience 89(3):901-907

3. Amrutkar DV, Ploug KB, Hay-Schmidt A, Porreca F, Olesen J, Jansen-Olesen I (2012) mRNA expression of 5-hydroxytryptamine 1B, 1D, and 1F receptors and their role in controlling the release of calcitonin gene-related peptide in the rat trigeminovascular system. Pain 153(4):830-838

4. Edvinsson JCA, Grell A, Warfvinge K, Sheykhzade M, Edvinsson L, Haanes KA (2020) Differences in pituitary adenylate cyclase-activating peptide and calcitonin gene-related peptide release in the trigeminovascular system. Cephalalgia 40(12):1296-1309

5. Haanes KA, Labastida-Ramirez A, Blixt FW, Rubio-Beltran E, Dirven CM Danser AH et al (2019) Exploration of purinergic receptors as potential anti-migraine targets using established pre-clinical migraine models. Cephalalgia 39(11):1421-1434

6. Edvinsson JC, Reducha PV, Sheykhzade M, Warfvinge K, Haanes KA, Edvinsson L (2021) Neurokinins and their receptors in the rat trigeminal system: Differential localization and release with implications for migraine pain. Mol Pain 17:17448069211059400

7. Goadsby PJ, Holland PR, Martins-Oliveira M, Hoffmann J, Schankin C, Akerman S (2017) Pathophysiology of migraine: a disorder of sensory processing. Physiol Rev 97(2):553-622

8. Bartsch T, Goadsby PJ (2003) The trigeminocervical complex and migraine: current concepts and synthesis. Curr Pain Headache Rep 7(5):371-376

9. Edvinsson JCA, Vigano A, Alekseeva A, Alieva E, Arruda R, De Luca C et al (2020) The fifth cranial nerve in headaches. J Headache Pain 21(1):65

10. Haanes KA, Edvinsson L (2019) Pathophysiological mechanisms in migraine and the identification of new therapeutic targets. CNS Drugs 33(6):525-537

11. Edvinsson L, Haanes KA (2021) Identifying new antimigraine targets: lessons from molecular biology. Trends Pharmacol Sci 42(4):217-225

12. Eftekhari S, Salvatore CA, Johansson $S$, Chen TB, Zeng Z, Edvinsson L (2015) Localization of CGRP, CGRP receptor, PACAP and glutamate in trigeminal ganglion. Relation to the blood-brain barrier. Brain Res 1600:93-109

13. Edvinsson JCA, Warfvinge K, Krause DN, Blixt FW, Sheykhzade M, Edvinsson L et al (2019) C-fibers may modulate adjacent Adelta-fibers through 
axon-axon CGRP signaling at nodes of Ranvier in the trigeminal system. J Headache Pain 20(1):105

14. Diener HC, Dodick DW, Goadsby PJ, Lipton RB, Almas M, Parsons B (2008) Identification of negative predictors of pain-free response to triptans: analysis of the eletriptan database. Cephalalgia 28(1):35-40

15. Rubio-Beltran E, Labastida-Ramirez A, Haanes KA, van den Bogaerdt A, Bogers A, Zanelli E et al (2019) Characterization of binding, functional activity, and contractile responses of the selective 5 -HT1F receptor agonist lasmiditan. Br J Pharmacol 176(24):4681-4695

16. Edvinsson JC, Maddahi A, Christensen IM, Reducha PV, Warfvinge K, Sheykhzade M et al (2022) Lasmiditan and 5-Hydroxytryptamine in the rat trigeminal system; expression, release and interactions with 5-HT1 receptors. J Headache Pain https://doi.org/10.1 186/s10194-022-01394-z

17. de Vries T, Villalon CM, MaassenVanDenBrink A (2020) Pharmacological treatment of migraine: CGRP and 5-HT beyond the triptans. Pharmacol Ther 107528

18. De Petrocellis L, Melck D, Bisogno T, Milone A, Di Marzo V (1999) Finding of the endocannabinoid signalling system in Hydra, a very primitive organism: possible role in the feeding response. Neuroscience 92(1):377-387

19. Burggren AC, Shirazi A, Ginder N, London ED (2019) Cannabis effects on brain structure, function, and cognition: considerations for medical uses of cannabis and its derivatives. Am J Drug Alcohol Abuse 45(6):563-579

20. Lowin T, Schneider M, Pongratz G (2019) Joints for joints: cannabinoids in the treatment of rheumatoid arthritis. Curr Opin Rheumatol 31(3):271-278

21. Herkenham M, Lynn AB, Little MD, Johnson MR, Melvin LS, de Costa BR et al (1990) Cannabinoid receptor localization in brain. Proc Natl Acad Sci U S A 87(5):1932-1936

22. Castillo PE, Younts TJ, Chavez AE, Hashimotodani Y (2012) Endocannabinoid signaling and synaptic function. Neuron 76(1):70-81

23. Katona I, Sperlagh B, Sik A, Kafalvi A, Vizi ES, Mackie K et al (1999) Presynaptically located $C B 1$ cannabinoid receptors regulate GABA release from axon terminals of specific hippocampal interneurons. J Neurosci 19(11):4544-4558

24. Schlicker E, Kathmann M (2001) Modulation of transmitter release via presynaptic cannabinoid receptors. Trends Pharmacol Sci 22(11):565-572

25. Katona I, Sperlagh B, Magloczky Z, Santha E, Kofalvi A, Czirjak S et al (2000) GABAergic interneurons are the targets of cannabinoid actions in the human hippocampus. Neuroscience 100(4):797-804

26. Caulfield MP, Brown DA (1992) Cannabinoid receptor agonists inhibit ca current in NG108-15 neuroblastoma cells via a pertussis toxin-sensitive mechanism. Br J Pharmacol 106(2):231-232

27. Lauckner JE, Hille B, Mackie K (2005) The cannabinoid agonist WIN55,212-2 increases intracellular calcium via CB1 receptor coupling to Gq/11 G proteins. Proc Natl Acad Sci U S A 102(52):19144-19149

28. Akerman S, Kaube H, Goadsby PJ (2004) Anandamide is able to inhibit trigeminal neurons using an in vivo model of trigeminovascular-mediated nociception. J Pharmacol Exp Ther 309(1):56-63

29. Akerman S, Holland PR, Goadsby PJ (2007) Cannabinoid (CB1) receptor activation inhibits trigeminovascular neurons. J Pharmacol Exp Ther 320(1):64-71

30. Ruparel NB, Patwardhan AM, Akopian AN, Hargreaves KM (2011) Desensitization of transient receptor potential ankyrin 1 (TRPA1) by the TRP vanilloid 1-selective cannabinoid arachidonoyl-2 chloroethanolamine. Mol Pharmacol 80(1):117-123

31. Engel MA, Izydorczyk I, Mueller-Tribbensee SM, Becker C, Neurath MF, Reeh PW (2011) Inhibitory CB1 and activating/desensitizing TRPV1-mediated cannabinoid actions on CGRP release in rodent skin. Neuropeptides 45(3):229-237

32. Hou M, Uddman R, Tajti J, Kanje M, Edvinsson L (2002) Capsaicin receptor immunoreactivity in the human trigeminal ganglion. Neurosci Lett 330(3):223-226

33. Fischer MJ, Messlinger K (2007) Cannabinoid and vanilloid effects of R(+)methanandamide in the hemisected meningeal preparation. Cephalalgia 27(5):422-428

34. Hillard CJ, Manna S, Greenberg MJ, DiCamelli R, Ross RA, Stevenson LA et al (1999) Synthesis and characterization of potent and selective agonists of the neuronal cannabinoid receptor (CB1). J Pharmacol Exp Ther 289(3):1427-1433
35. Bhatt DK, Gupta S, Jansen-Olesen I, Andrews JS, Olesen J (2013) NXN-188, a selective nNOS inhibitor and a 5-HT1B/1D receptor agonist, inhibits CGRP release in preclinical migraine models. Cephalalgia 33(2):87-100

36. Egea SC, Dickerson IM (2012) Direct interactions between calcitonin-like receptor (CLR) and CGRP-receptor component protein (RCP) regulate CGRP receptor signaling. Endocrinology 153(4):1850-1860

37. Walker CS, Eftekhari S, Bower RL, Wilderman A, Insel PA, Edvinsson L et al (2015) A second trigeminal CGRP receptor: function and expression of the AMY1 receptor. Ann Clin Transl Neurol 2(6):595-608

38. Edvinsson L, Edvinsson JCA, Haanes KA (2022) Biological and small molecule strategies in migraine therapy with relation to the calcitonin gene-related peptide family of peptides. Br J Pharmacol 179(3):371-380

39. Walker CS, Raddant AC, Woolley MJ, Russo AF, Hay DL (2018) CGRP receptor antagonist activity of olcegepant depends on the signalling pathway measured. Cephalalgia 38(3):437-451

40. Price TJ, Helesic G, Parghi D, Hargreaves KM, Flores CM (2003) The neuronal distribution of cannabinoid receptor type 1 in the trigeminal ganglion of the rat. Neuroscience 120(1):155-162

41. Hougaard Pedersen S, Maretty L, Ramachandran R, Sibbesen JA, Yakimov $\checkmark$, Elgaard-Christensen R et al (2016) RNA sequencing of trigeminal ganglia in Rattus Norvegicus after glyceryl Trinitrate infusion with relevance to migraine. PLoS One 11(5):e0155039

42. Price TJ, Patwardhan A, Akopian AN, Hargreaves KM, Flores CM (2004) Modulation of trigeminal sensory neuron activity by the dual cannabinoid-vanilloid agonists anandamide, $\mathrm{N}$-arachidonoyl-dopamine and arachidonyl-2-chloroethylamide. Br J Pharmacol 141(7):1118-1130

43. Richardson JD, Aanonsen L, Hargreaves KM (1998) Antihyperalgesic effects of spinal cannabinoids. Eur J Pharmacol 345(2):145-153

44. Van Der Stelt M, Di Marzo V (2004) Endovanilloids. Putative endogenous ligands of transient receptor potential vanilloid 1 channels. Eur J Biochem 271(10):1827-1834

45. Akopian AN, Ruparel NB, Jeske NA, Patwardhan A, Hargreaves KM (2009) Role of ionotropic cannabinoid receptors in peripheral antinociception and antihyperalgesia. Trends Pharmacol Sci 30(2):79-84

46. Muller C, Morales P, Reggio PH (2018) Cannabinoid Ligands Targeting TRP Channels. Front Mol Neurosci 11:487

47. Raboune S, Stuart JM, Leishman E, Takacs SM, Rhodes B, Basnet A et al (2014) Novel endogenous $\mathrm{N}$-acyl amides activate TRPV1-4 receptors, BV-2 microglia, and are regulated in brain in an acute model of inflammation. Front Cell Neurosci 8:195

48. Casarotto PC, Terzian AL, Aguiar DC, Zangrossi H, Guimaraes FS, Wotjak CT et al (2012) Opposing roles for cannabinoid receptor type-1 (CB (1)) and transient receptor potential vanilloid type-1 channel (TRPV1) on the modulation of panic-like responses in rats. Neuropsychopharmacol 37(2):478-486

49. Tognetto M, Amadesi S, Harrison S, Creminon C, Trevisani M, Carreras M et al (2001) Anandamide excites central terminals of dorsal root ganglion neurons via vanilloid receptor-1 activation. J Neurosci 21(4):1104-1109

50. Zygmunt PM, Petersson J, Andersson DA, Chuang H, Sorgard M, Di Marzo $\checkmark$ et al (1999) Vanilloid receptors on sensory nerves mediate the vasodilator action of anandamide. Nature 400(6743):452-457

51. Smart D, Gunthorpe MJ, Jerman JC, Nasir S, Gray J, Muir Al et al (2000) The endogenous lipid anandamide is a full agonist at the human vanilloid receptor (hVR1). Br J Pharmacol 129(2):227-230

52. Starkus J, Jansen C, Shimoda LMN, Stokes AJ, Small-Howard AL, Turner H (2019) Diverse TRPV1 responses to cannabinoids. Channels (Austin) 13(1):172-191

53. Doherty EM, Fotsch C, Bo Y, Chakrabarti PP, Chen N, Gavva N et al (2005) Discovery of potent, orally available vanilloid receptor-1 antagonists. Structure-activity relationship of $\mathrm{N}$-aryl cinnamides. J Med Chem 48(1):71-90

54. Summ O, Holland PR, Akerman S, Goadsby PJ (2011) TRPV1 receptor blockade is ineffective in different in vivo models of migraine. Cephalalgia 31(2):172-180

55. Edvinsson L, Haanes KA (2021) Identifying New Antimigraine Targets: Lessons from Molecular Biology. Trends Pharmacol Sci 42(4):217-225

\section{Publisher's Note}

Springer Nature remains neutral with regard to jurisdictional claims in published maps and institutional affiliations. 